\title{
Aldehyde-forming fatty acyl-CoA reductase from cyanobacteria: expression, purification and characterization of the recombinant enzyme
}

\author{
Fengming Lin ${ }^{1,2}$, Debasis Das ${ }^{1}$, Xiaoxia N. Lin ${ }^{2}$ and E. Neil G. Marsh ${ }^{1,3}$ \\ 1 Department of Chemistry, University of Michigan, Ann Arbor, MI, USA \\ 2 Department of Chemical Engineering, University of Michigan, Ann Arbor, MI, USA \\ 3 Department of Biological Chemistry, University of Michigan, Ann Arbor, MI, USA
}

\section{Keywords}

aldehyde formation; biofuels; cyanobacteria; enzyme mechanism; hydrocarbon metabolism

\section{Correspondence \\ N. Marsh, Department of Chemistry, University of Michigan, Ann Arbor, MI 48109, USA \\ Fax: +7346153790 \\ Tel: +734 7636096 \\ E-mail: nmarsh@umich.edu \\ X. N. Lin, Department of Chemical \\ Engineering, University of Michigan, \\ Ann Arbor, MI 48109, USA \\ Fax: +734 7647453 \\ Tel: +7346478026 \\ E-mail: ninalin@umich.edu}

(Received 17 April 2013, revised 21 June 2013, accepted 22 July 2013)
Long-chain acyl-CoA reductases (ACRs) catalyze a key step in the biosynthesis of hydrocarbon waxes. As such they are attractive as components in engineered metabolic pathways for 'drop in' biofuels. Most ACR enzymes are integral membrane proteins, but a cytosolic ACR was recently discovered in cyanobacteria. The ACR from Synechococcus elongatus was overexpressed in Escherichia coli, purified and characterized. The enzyme was specific for NADPH and catalyzed the reduction of fatty acyl-CoA esters to the corresponding aldehydes, rather than alcohols. Stearoyl-CoA was the most effective substrate, being reduced more rapidly than either longer or shorter chain acyl-CoAs. ACR required divalent metal ions, e.g. $\mathrm{Mg}^{2+}$, for activity and was stimulated $\sim 10$-fold by $\mathrm{K}^{+}$. The enzyme was inactivated by iodoacetamide and was acylated on incubation with stearoyl-CoA, suggesting that reduction occurs through an enzyme-thioester intermediate. Consistent with this, steady state kinetic analysis indicates that the enzyme operates by a 'ping-pong' mechanism with $k_{\text {cat }}=0.36 \pm 0.023 \mathrm{~min}^{-1}, K_{\mathrm{m}}$ (stearoyl-CoA) $=31.9 \pm 4.2 \mu \mathrm{M}$ and $K_{\mathrm{m}}(\mathrm{NADPH})=35.6 \pm 4.9 \mu \mathrm{M}$. The slow turnover number measured for ACR poses a challenge for its use in biofuel applications where highly efficient enzymes are needed.

doi:10.1111/febs. 12443

\section{Introduction}

Long-chain acyl-CoA reductases (ACRs) catalyze a key step in the biosynthesis of waxes (long-chain alkanes) and wax esters (esters of long-chain carboxylic acids with long-chain alcohols) [1]. These aliphatic molecules are biosynthesized by a variety of organisms including plants, birds, insects and green algae [2-6]. They have attracted interest as potential biofuels because they have high energy density and have the potential to be used directly as substitutes for gasoline, diesel and jet fuel without costly and energy-intensive chemical conversion [7-9].

Most long-chain ACRs that have been characterized are membrane-associated proteins. Those that are involved in the biosynthesis of wax esters catalyze reduction of fatty acyl-CoA esters to alcohols $[3,10$ 12], presumably through an aldehyde intermediate. The alcohol subsequently undergoes transesterification with a second fatty acyl-CoA molecule to give the wax

\footnotetext{
Abbreviations

ACR, acyl-CoA reductase; cACR, cyanobacterial acyl-CoA reductase; cADO, cyanobacterial aldehyde deformylating oxygenase; FID, flame ionization detector; IAA, iodoacetamide; luxC, myristoyl-CoA reductase; MCR, malonyl-CoA reductase; THP, tris(hydroxylpropyl) phosphine.
} 
ester. The second group of reductases is involved in alkane wax biosynthesis and reduces acyl-CoA esters only to the aldehyde oxidation state. The latter group includes enzymes from bacteria such as Acinetobacter calcoaceticus [13], green algae such as Botyrococcus braunii [4] and plants, e.g. Pisum sativum [3]. In the alkane biosynthesis pathway, these aldehydes subsequently undergo decarbonylation by aldehyde decarbonylase to yield alkanes with odd numbers of carbon atoms [1]; this pathway is illustrated in Fig. 1.

The difficulties inherent in expressing and purifying membrane proteins have hindered mechanistic studies on the enzymes involved in hydrocarbon biosynthesis. Recently, however, an alkane biosynthesis pathway was identified in some strains of cyanobacteria that, surprisingly, comprises soluble enzymes [14]. When the cyanobacterial acyl-CoA reductase (cACR) and aldehyde decarbonylase (now known as cyanobacterial aldehyde deformylating oxygenase, cADO) enzymes were heterologously introduced into Escherichia coli, alkanes were produced. Although the rate of production was relatively modest, $300 \mathrm{mg} \cdot \mathrm{L}^{-1}$ over $40 \mathrm{~h} \mathrm{[14]}$, this nevertheless represents a promising biological route to produce hydrocarbon biofuels from renewable raw materials. Several recent papers have reported investigations on aspects of the cADO reaction [1519]; however, cACR has not been characterized.

In this study we report the overexpression, purification and initial characterization of cACR from Synechococcus elongatus PCC7942. By optimizing the enzyme assay conditions, activity was increased $\sim 10$-fold from that reported previously [14]. The enzyme was found to be dependent upon both $\mathrm{K}^{+}$and $\mathrm{Mg}^{2+}$ for activity and is irreversibly inactivated by iodoacetamide (IAA). Incubation with stearoyl-CoA resulted in acylation of $\mathrm{cACR}$, indicating that an enzyme-thioester intermediate is involved in reduction. The enzyme exhibited a pronounced selectivity towards reduction of stearoyl-CoA esters, with both longer and shorter chain acyl-CoA esters being reduced more slowly.

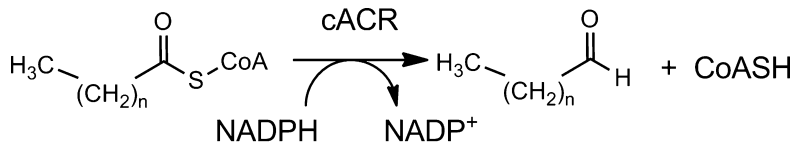

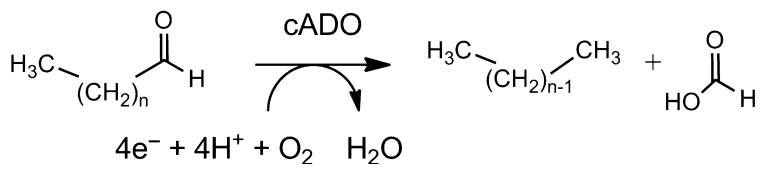

Fig. 1. Reactions catalyzed by $C A C R$ and $C A D O$ which are involved in the alkane biosynthesis pathway in cyanobacteria.

\section{Results}

\section{Expression and purification of CACR}

Various strains of cyanobacteria produce alkanes; however, the enzymes from Nostoc punctiforme PCC73102 and S. elongatus PCC7942 produced the highest titers of alkanes when heterologously expressed with cADO in E. coli [14]. Therefore, our efforts to characterize cACR focused on the enzymes from these strains. Although $N$. punctiforme cACR was expressed at high levels in E. coli at $37{ }^{\circ} \mathrm{C}$, the protein was produced exclusively as inclusion bodies. Extensive efforts to improve solubility, including lowering the growth temperature to $18{ }^{\circ} \mathrm{C}$, using different culture media and repositioning the His-tag from the $\mathrm{N}$-terminal to C-terminal of cACR, were met with little success. Attempts to purify and refold cACR from inclusion bodies were also unsuccessful.

Attempts to overexpress and purify S. elongatus cACR in E. coli were more successful. Overnight induction at $18{ }^{\circ} \mathrm{C}$ of a $c A C R$ gene construct that incorporated a C-terminal His-tag resulted in the expression of protein that was $\sim 50 \%$ soluble. However, placing the His-tag at the $\mathrm{N}$-terminus or gene expression at higher temperatures resulted in the protein being produced almost exclusively as inclusion bodies. The purification of S. elongatus cACR could be accomplished by standard methods utilizing affinity chromatography on a nickel-nitrilotriacetic acid (NTA) column (see Materials and methods). cACR was eluted from the column using a linear gradient of 50-250 mm imidazole to yield protein that was $>95 \%$ pure (Fig. 2), which was used for subsequent experiments.

Purified cACR was found to be quite unstable and tended to precipitate after 3-4 days when stored at $4{ }^{\circ} \mathrm{C}$, although it could be stored for prolonged periods at $-80{ }^{\circ} \mathrm{C}$ without loss of activity. Consistent with this, a small amount of proteolysis always appeared to accompany purification, despite attempts to limit degradation by including protease inhibitors in the purification buffer, as evidenced by SDS/PAGE (Fig. 2). The stability of the enzyme could be improved to some degree by including $500 \mathrm{~mm} \mathrm{NaCl}$ and/or $0.2 \%$ Chaps in the storage buffer.

\section{Characterization of the reaction}

As noted above, long-chain ACR enzymes may catalyze the reduction of acyl-CoA esters to either aldehydes or alcohols. A preliminary investigation [14] of the activity of CACR indicated that the enzyme 


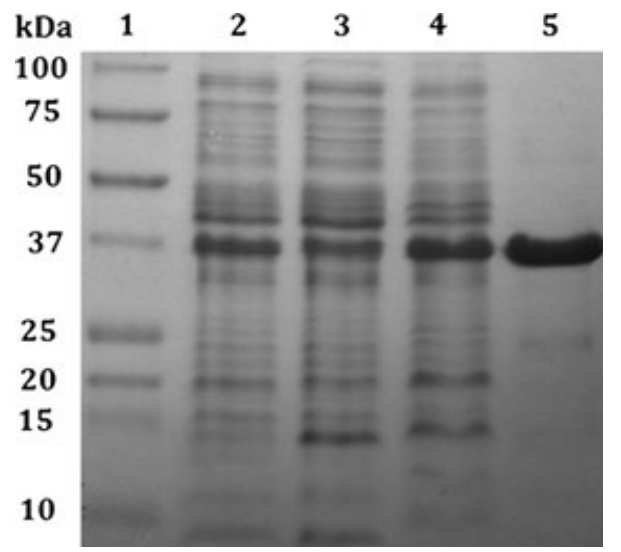

Fig. 2. SDS/PAGE analysis of the purification scheme of $C A C R$ from S. elongatus PCC7942 expressed in E. coli. Protein expression was performed at $18{ }^{\circ} \mathrm{C}$ overnight: lane 1, protein standards; lane 2, whole cells; lane 3, supernatant after cell lysis; lane 4, cell pellet after lysis; lane 5, purified CACR after the Ni-affinity column.

specifically produced aldehydes as products. Using the assay conditions described previously [14] as a starting point, we examined the activity of cACR using stearoyl-CoA $(400 \mu \mathrm{M})$ and NADPH $(1 \mathrm{mM})$ as substrates and analyzed the products of reaction by GC. The enzyme was specific for NADPH, with no aldehyde being formed if NADH was substituted instead. We confirmed that no octadecanol could be detected in the products of the reaction. Although octadecanal was readily detected, its rate of formation was extremely slow: only $\sim 0.6 \mu \mathrm{mol}$ octadecanal. $\mathrm{h}^{-1}$ was produced per micromole of purified cACR. We therefore conducted a comprehensive survey of assay conditions in an attempt to improve enzyme activity.

We first investigated the sensitivity of enzyme activity to $\mathrm{pH}$. Activity was found to vary only slightly with $\mathrm{pH}$ and was maximal at $\mathrm{pH}$ 8.0. Next, given the poor stability of the enzyme and its tendency to precipitate, we examined the effect of various additives such as non-ionic detergents that are known to stabilize enzymes. Whereas most detergents tested had little effect on cACR activity, or were inhibitory at higher concentrations, chaps was found to modestly increase activity (Fig. $3 \mathrm{~A}$ ) by $\sim 75 \%$ at $0.2 \%$. We also examined the effect of thiol-directed reducing agents on enzyme activity. Whereas 2-mercaptoethanol had no effect on activity, high concentrations (5 mM) of dithiothreitol or glutathione inhibited cACR activity (Fig. 3B). In contrast, inclusion of a high concentration $(20 \mathrm{~mm})$ of the phosphine-based reductant tris(hydroxylpropyl) phosphine (THP) increased activity $\sim 2$ fold. Increasing THP concentrations beyond $20 \mathrm{~mm}$ resulted in little improvement in activity. Lastly, we investigated the addition of BSA to the assay, which has been found to stabilize many enzymes. Inclusion of up to $1 \mathrm{mg} \cdot \mathrm{mL}^{-1}$ of BSA resulted in an increase in activity of $\sim 3$-fold.

\section{Requirement for divalent and monovalent cations}

Many enzymes that bind nucleotide-based cofactors exhibit a requirement for divalent metal ions; we therefore investigated the metal ion dependence of cACR activity. Activity was highly dependent on the presence of divalent cations in the buffer; $\mathrm{Mg}^{2+}, \mathrm{Mn}^{2+}$ and $\mathrm{Ca}^{2+}$ all supported activity (Fig. 3C). However, higher concentrations of $\mathrm{Mn}^{2+}(2 \mathrm{mM})$ and $\mathrm{Ca}^{2+}(5 \mathrm{~mm})$ were inhibitory as they caused precipitation of the acyl-CoA substrate in the assay buffer, a problem that has been noted previously [20].

We had initially included $250 \mathrm{~mm} \mathrm{NaCl}$ in cACR assays because moderately high concentrations of salt appeared to stabilize the enzyme against precipitation during purification. Unexpectedly, however, we noticed that substitution of $\mathrm{KCl}$ for $\mathrm{NaCl}$ in the assay buffer increased ACR activity $\sim 10$-fold, with optimal activity obtained with $250 \mathrm{~mm} \mathrm{KCl}$ (Fig. 3D). This suggests that a specific requirement for $\mathrm{K}^{+}$ion, with $\mathrm{Na}^{+}$ being weakly stimulatory, rather than a general effect of ionic strength is responsible for the increased activity and stability of the enzyme in the presence of salt.

By combining the results from the various optimization trials, it was possible to significantly improve the activity of the enzyme, although we note that the increases in activity noted above for the individual components of the assay buffer are not additive. The optimized assay buffer contained $50 \mathrm{~mm}$ Tris/ $\mathrm{HCl}, \mathrm{pH}$ $7.5,250 \mathrm{~mm} \mathrm{KCl}, 2 \mathrm{~mm} \mathrm{MgCl}_{2}, 1 \mathrm{mg} \cdot \mathrm{mL}^{-1} \mathrm{BSA}$, $20 \mathrm{~mm}$ THP, $0.2 \%$ Chaps, $1 \mathrm{~mm}$ NADPH, $400 \mu \mathrm{m}$ stearoyl-CoA and $10 \mu \mathrm{M}$ cACR. Under these conditions cACR activity was $17.3 \mu \mathrm{mol}$ octadecanal $\cdot \mathrm{h}^{-1} \cdot \mu \mathrm{mol}$ $\mathrm{CACR}^{-1}$, an improvement of 26 -fold over the initially measured activity. The cACR activity was increased $\sim 10$-fold compared with that reported previously using oleoyl-CoA as a substrate [14].

\section{Substrate specificity}

The substrate range of $\mathrm{cACR}$ is of particular interest for biotechnological applications. We examined the activity of cACR with acyl-CoA esters of different chain lengths ranging from 20 to eight carbon atoms. The relative rates of reduction were measured by following the change in NADPH absorbance at $340 \mathrm{~nm}$ 

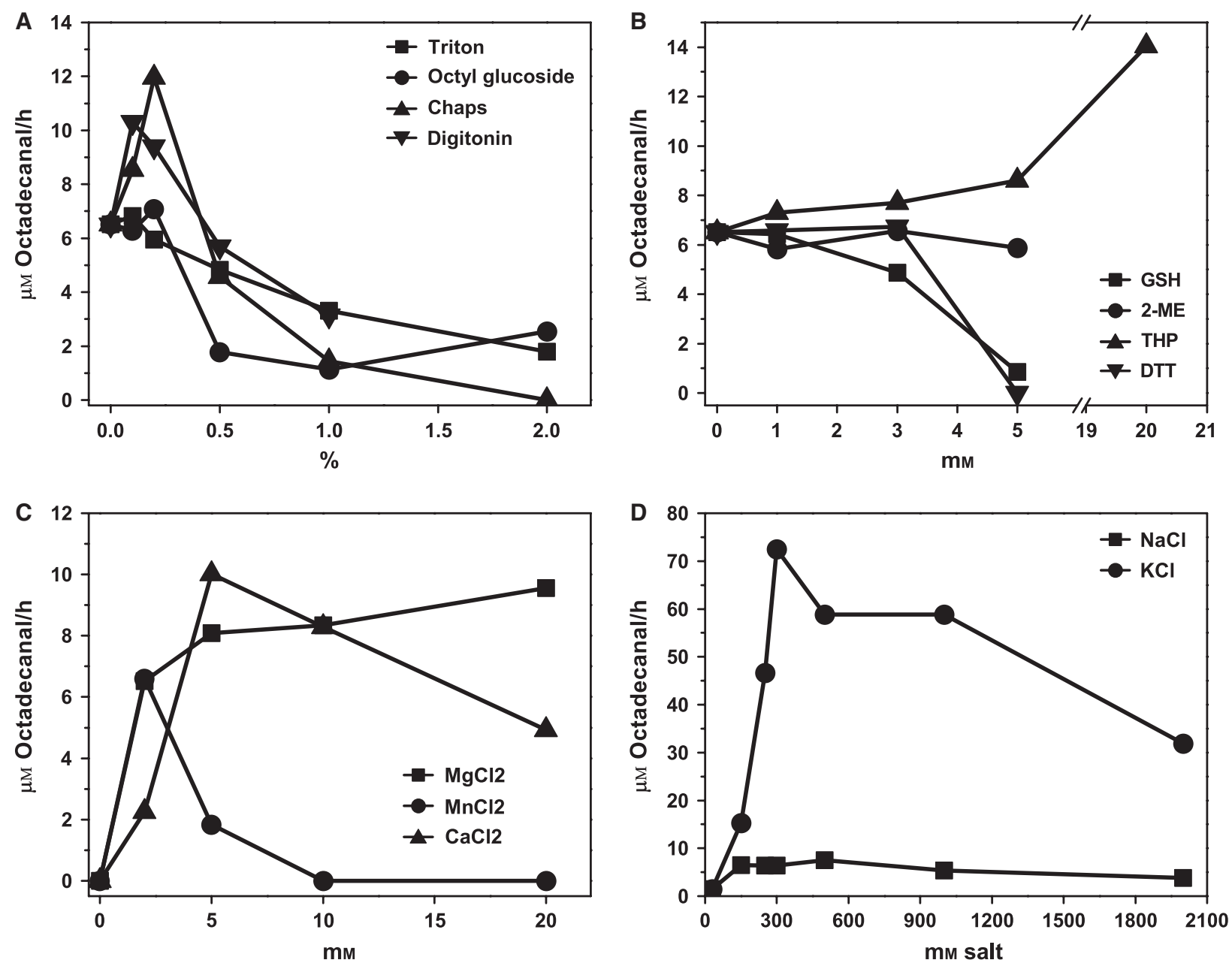

Fig. 3. Dependence of $c A C R$ activity on detergents, reducing agents and metal ions. Effects of (A) detergents, (B) reducing agents, (C) divalent metal ions and (D) $\mathrm{Na}^{+}$and $\mathrm{K}^{+}$ions. All assays were carried out at $37{ }^{\circ} \mathrm{C}$ with shaking at $200 \mathrm{rpm}$. 2-ME, 2-mercaptoethanol; DTT, dithiothreitol; GSH, glutathione.

in assays that contained $400 \mu \mathrm{m}$ acyl-CoA and $200 \mu \mathrm{M}$ NADPH (Fig. 4). The enzyme showed a marked preference for stearoyl-CoA, which was reduced over twice as fast as the eicosanoyl-CoA (C20:0). cACR showed progressively lower activity with acyl-CoAs shorter than stearoyl-CoA to the point at which no activity was detectable for octanoyl-CoA, the shortest substrate tested. Oleoyl-CoA (C18:1) was also a poor substrate, indicating that a cis double bond is not well accommodated by the enzyme's active site.

\section{Kinetic properties}

The significant improvement of cACR activity that resulted from optimization of the assay conditions made it possible to follow the reaction in real time by monitoring NADPH oxidation using absorbance at $340 \mathrm{~nm}$, rather than by GC, thus greatly facilitating kinetic anal-

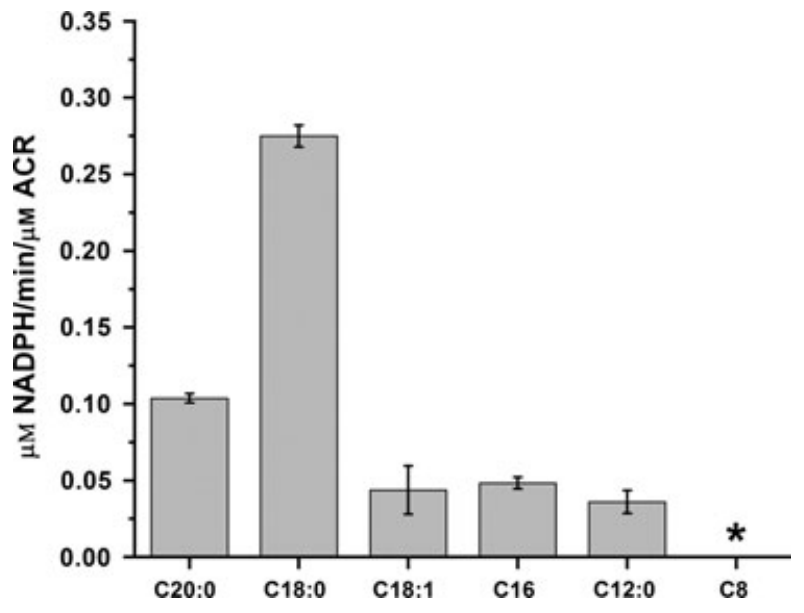

Fig. 4. The substrate specificity of CACR for acyl-CoA esters of various chain lengths. 
ysis of the reaction. We determined the enzyme activity of cACR as a function of stearoyl-CoA and NADPH concentrations (Fig. 5). Global fitting of the data to either a ternary mechanism (Eqn 1; see later) or a 'pingpong' mechanism (Eqn 2) indicated that a 'ping-pong' mechanism is more likely, since fitting the data to a ternary mechanism gave values for $K_{\mathrm{ia}}$ that were unrealistically low (data not shown). From the global fit to Eqn (2) the steady state kinetic parameters are $k_{\text {cat }}=0.36 \pm 0.023 \mathrm{~min}^{-1}, \quad K_{\mathrm{m}} \quad$ (stearoyl-CoA $)=31.9 \pm$ $4.2 \mu \mathrm{M}$ and $K_{\mathrm{m}(\mathrm{NADPH})}=35.6 \pm 4.9 \mu \mathrm{M} ; R^{2}=0.92$.

\section{Formation of acyl-enzyme intermediate}

Other aldehyde-forming ACRs, e.g. myristoyl-CoA reductase (luxC) [21] and malonyl-CoA reductase (MCR) [22], have been shown to form an intermediate acyl-enzyme thioester through an active site cysteinyl residue. The sensitivity to thiol-reducing agents noted above further suggested a role for an active site cysteine in the mechanism of $\mathrm{CACR}$. We therefore investigated whether cACR was inactivated by IAA. As shown in Fig. 6A, IAA rapidly inactivated cACR. (The residual cACR activity evident in Fig. 6A is the result of incomplete alkylation under the conditions of the experiment, as evident from the mass spectral analysis of the IAA-treated enzyme, Fig. 6B, trace V. Incubation of cACR with $1 \mathrm{~mm}$ IAA at room temperature for 5 min completely inactivated the enzyme.) Inclusion of stearoyl-CoA $(200 \mu \mathrm{M})$ in the reaction mixture afforded protection against inactivation. The initial drop in activity observed when the enzyme is incu-

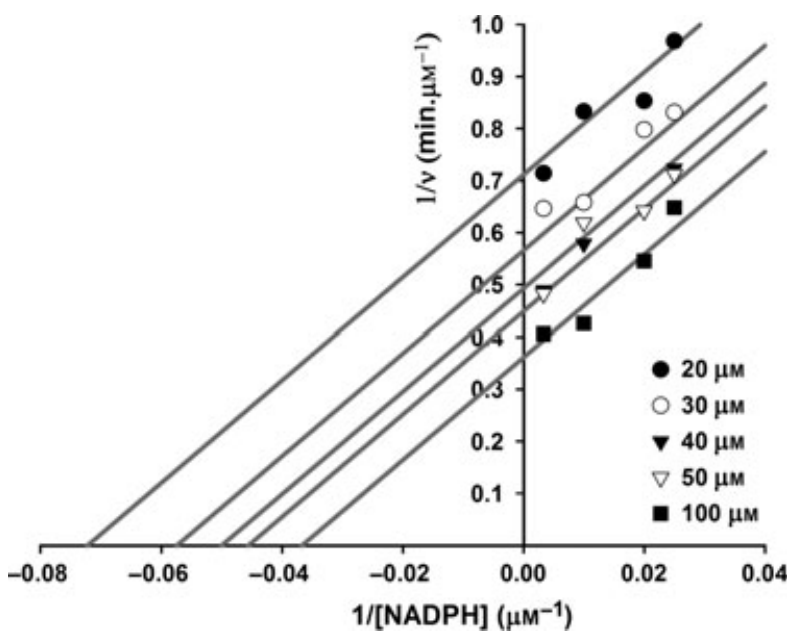

Fig. 5. Steady state kinetic analysis of cACR. Double-reciprocal plots for varying [NADPH] at different fixed concentrations of stearoyl-CoA (concentrations indicated in the figure). The lines represent the best fit of the data to a 'ping-pong' mechanism. bated in the presence of both IAA and stearoyl-CoA probably arises from competition between the two reagents for the active site cysteine. However, once acylated by stearoyl-CoA the enzyme is protected from inactivation by IAA and the cACR activity remains unchanged. Under the conditions of the experiment the enzyme itself is not particularly stable, resulting in $\sim 25 \%$ of the activity being lost during the experiment.

To demonstrate the formation of acylated enzyme, cACR was incubated with stearoyl-CoA $(400 \mu \mathrm{M})$ in the presence of NADPH and the enzyme was subjected to electrospray-MS analysis. The mass of native enzyme was determined as $42626.2 \mathrm{Da}$ in excellent agreement with the predicted mass of $42626.26 \mathrm{Da}$ (Fig. 6B, trace I). In the absence of NADPH, cACR was completely converted to the acyl-enzyme upon incubation with stearoyl-CoA, resulting in an increase
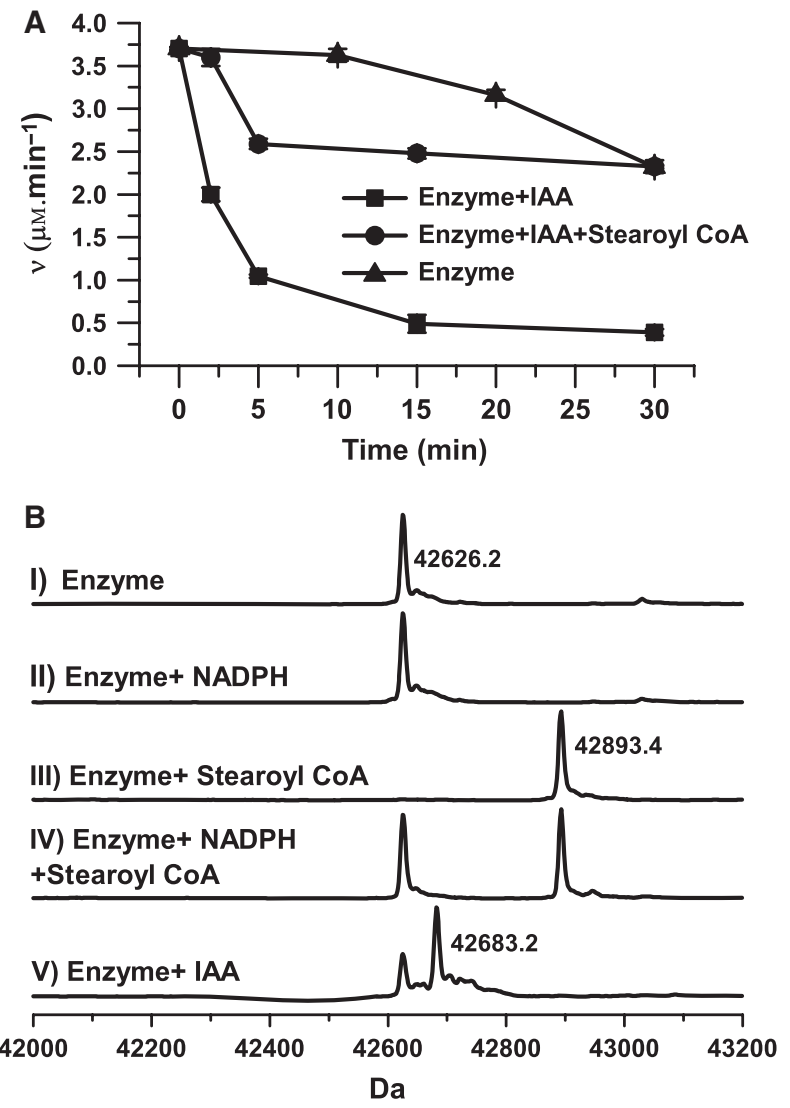

Fig. 6. Formation of acyl-enzyme intermediate. (A) Inactivation of CACR by IAA. (B) Detection of enzyme-thioester intermediate by LC-MS. Shown are ES-MS spectra of CACR (I) in assay buffer; (II) after incubation with NADPH; (III) after incubation with stearoyl-CoA; (IV) after incubation with stearoyl-CoA and NADPH; and (V) after incubation with IAA. Spectra show peaks for unmodified enzyme, $M_{\mathrm{r}}=42626.2 \pm 2.0 \mathrm{Da}$; acyl-enzyme, $M_{\mathrm{r}}=42893.4 \pm 2.0 \mathrm{Da}$; and IAA-alkylated enzyme, $M_{\mathrm{r}}=42683.4 \pm 2.0 \mathrm{Da}$. 
in mass to $42893.4 \mathrm{Da}$ (Fig. 6B, trace III). The difference in mass $(+267 \mathrm{Da})$ corresponds well with that predicted for acylation by stearoyl-CoA (+266 Da). When the enzyme was incubated with both stearoyl$\mathrm{CoA}$ and NADPH, so that turnover could occur (Fig. 6B, trace IV), the acyl-enzyme accumulated to comprise $\sim 50 \%$ of the enzyme. This observation suggests that the rates of acylation and reduction are approximately the same. Together, these results point to the formation of an acyl thioester on an active site cysteinyl residue as an intermediate in the mechanism of reduction. We note that these results also exclude adventitious oxidation of the active site cysteine as a reason for the very low activity of the enzyme.

\section{Discussion}

The cACR is unusual in being a cytosolic enzyme rather than a membrane-associated protein, which is the case for ACR enzymes characterized from plants [3,11] and green algae [4]. Even so, the limited stability and solubility of the protein complicated efforts to overexpress and purify cACR in E. coli. We were unable to express ACR from $N$. punctiforme PCC 73102 in soluble form; however, ACR from S. elongatus PCC7942 could be produced, in part, as soluble protein by expression at low temperature and was purified to near homogeneity by affinity chromatography on a nickel-NTA column. Only aldehydes were detected as the products of acyl-CoA reduction, in contrast to some other ACRs that reduce their substrates to alcohols [3,11].

By screening a variety of assay conditions, we were able to significantly increase the activity of cACR. Low concentrations of non-ionic detergents, BSA and reducing agents all increase activity, presumably by preventing aggregation and maintaining cysteine in a reduced state. The most significant effects on activity are exerted by metal ions. CACR appears to require divalent metal ions, such as $\mathrm{Mg}^{2+}$, and be strongly stimulated by $\mathrm{K}^{+}$ions. Under the optimized assay conditions cACR activity was about 10 -fold higher than previously reported [14]; even so, $k_{\text {cat }}=$
$0.36 \mathrm{~min}^{-1}$ is still very low compared with most enzymes. Although in most cases the plant and algal ACR enzymes have not been fully purified or kinetically characterized in such detail, they also appear to be similarly slow $[3,4,11]$.

The ACRs that have been characterized from Marinobacter aqueaeolei VT8 [10] and Acinetobacter calcoaceticus [13] exhibit a preference for palmitoyl-CoA. In contrast, cACR is more active with stearoyl-CoA. This observation is in accord with reports that heptadecane is the most abundant alkane found in cyanobacteria, followed by pentadecane [14]. The cyanobacterial aldehyde decarbonylase does not exhibit pronounced selectivity for aldehydes of different chain lengths [19]; this suggests that the chain length of alkane products is primarily determined by the distribution of aldehyde precursors, which are produced by cACR.

cACR is identified as a member of the NAD $(\mathrm{P}) \mathrm{H}$ binding Rossmann fold superfamily on the basis of sequence alignments; however, it shares no overall sequence similarity with other, better characterized aldehyde-generating reductases such as luxC [21], or with MCR [23], aspartate semialdehyde dehydrogenase [24] and glycderaldehyde-3-phosphate dehydrogenase, for which X-ray structures have been solved $[22,25,26]$. For all these enzymes, the formation of an acylenzyme thio-ester intermediate with an active site cysteinyl residue is an established feature of the mechanism $[21,22,24]$. The acylation of cACR by stearoyl$\mathrm{CoA}$ and its inactivation by IAA suggests that cACR operates by a similar mechanism. cACR from $S$. elongatus PCC7942 contains six cysteine residues, but only Cys293 is conserved across all the cACR homologs and therefore is the most likely candidate for the active site residue.

The formation of a covalent enzyme-substrate intermediate is consistent with steady state kinetic data that support a 'ping-pong' mechanism for acyl-CoA reduction by cACR as shown in Scheme 1. A 'ping-pong' mechanism is also indicated for other aldehyde-forming reductases. Notably for MCR a recent crystallographic study showed that $\mathrm{CoA}$ and $\mathrm{NADP}^{+}$both bind at the

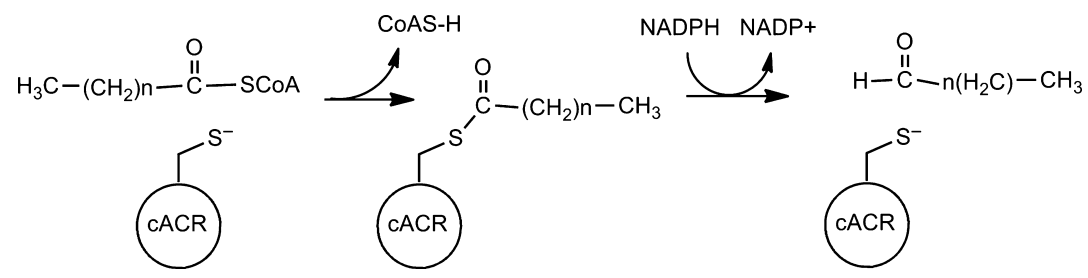

Scheme 1. Proposed 'ping-pong' mechanism for acyl-CoA reduction by CACR. 
same site [22] so that the formation of a ternary complex is physically impossible. One important point to emerge from these studies is that cACR catalyzes the reduction of acyl-CoA esters very slowly. This is somewhat puzzling because the reaction does not have an intrinsically high activation barrier and MCR catalyzes the chemically identical reduction of malonyl-CoA with $k_{\text {cat }} \sim 20000$-fold faster than that of cACR [23]. It is currently unclear whether this reflects the endogenous activity of the enzyme in the cell or whether some other (unknown) activation factor is necessary. The enzyme will also accept acyl-(acyl carrier proteins) as substrates [14]. However, these are turned over more slowly than acyl-CoA esters, suggesting that this is not the reason for the slow rate of reduction.

We note that the second enzyme of the alkane biosynthesis pathway in cyanobacteria, cADO, is also extremely slow with $k_{\text {cat }} \sim 1 \min ^{-1}$ [19]. Moreover, it is currently unclear why cyanobacteria produce alkanes, and indeed not all strains do so. It is possible that they are produced as a side-reaction of some other metabolic pathway, or perhaps as signaling molecules that are only needed in very small amounts. In such a case, there may simply be no evolutionary pressure on the enzymes to catalyze these reactions more rapidly. The low catalytic activity of these enzymes presents a significant challenge for their use in biotechnological applications associated with biofuel production where highly efficient enzymes are needed. Further elucidation of the mechanisms of both ACR and cADO, together with improvements in their catalytic efficiency through protein engineering, will be needed to realize the potential of this hydrocarbon biosynthesis pathway for biofuel applications.

\section{Materials and methods}

\section{Materials}

The genes encoding cACRs from $N$. punctiforme PCC 73102 (NCBI accession number YP 001865324) and S. elongatus PCC7942 (NCBI accession number YP_400611) were synthesized commercially by GenScript USA Inc. (Piscataway, NJ, USA) and codon-optimized for expression in E. coli. Acyl-CoA esters (C8, C12, C14, C16, C18 and C18:1) were purchased from Sigma (Milwaukee, WI, USA); C20 acyl-CoA ester was from Avanti Polar Lipids (Alabaster, AL, USA). NADPH was obtained from MP Biomedicals (Solon, OH, USA). The detergents digitonin, Chaps, Triton X 100 and octyl glucoside were obtained from Fisher (Pittsburgh, PA, USA). Reducing agents 2-mercaptoethanol, dithiothreitol and glutathione were purchased from Fisher; $0.5 \mathrm{M}$ THP solution was obtained from EMD Millipore, (Billerica, MA, USA).

\section{Protein expression}

The synthetic genes were cloned into the expression vector pET-28b as NdeI/BamHI or NcoI/XhoI fragments to introduce either an N-terminal or C-terminal His-tag to facilitate purification. The plasmids were transformed into E. coli strain BL21 (DE3) (Invitrogen) for protein expression. Protein expression was performed at either $37^{\circ} \mathrm{C}$ or $18{ }^{\circ} \mathrm{C}$ in $1 \mathrm{~L} \mathrm{LB}$ medium supplemented with $50 \mu \mathrm{g} \cdot \mathrm{mL}^{-1}$ kanamycin. Cell cultures were grown to an $D_{600}$ of $0.6-0.8$ and gene expression was induced with $0.1 \mathrm{~mm}$ isopropyl- $\beta$ D-thiogalactopyranoside for $3 \mathrm{~h}$ or overnight before harvesting by centrifugation.

\section{Protein purification}

All steps were performed at $4{ }^{\circ} \mathrm{C}$ on ice. In a typical purification $7 \mathrm{~g}$ (damp weight) of cells were resuspended in $50 \mathrm{~mL}$ binding buffer (20 mM Tris $/ \mathrm{HCl}, \mathrm{pH} 8.0,500 \mathrm{~mm} \mathrm{NaCl}$, $5 \mathrm{~mm}$ imidazole, 5\% glycerol, $1 \mathrm{~mm}$ THP). Then $0.5 \mathrm{mg} \cdot \mathrm{mL}^{-1}$ of lysozyme, 1 protease inhibitor tablet (Roche), $1 \mu \mathrm{L}$ of DNAse (Novagen) and $1 \mathrm{~mm}$ THP were added to the cell suspension and incubated on ice for $1 \mathrm{~h}$ with shaking. The cells were lysed by sonication at maximum power using $2 \mathrm{~s}$ pulses separated by $8 \mathrm{~s}$ to prevent overheating for a total time of $30 \mathrm{~min}$. The supernatant was separated from cell debris by centrifugation at $15000 \mathrm{~g}$ at $4{ }^{\circ} \mathrm{C}$ for $30 \mathrm{~min}$. Protein purification was performed using an ÄKTAexplorer ${ }^{\mathrm{TM}}$ chromatography system. The supernatant was loaded onto a HisTrap column (GE Healthcare) and the column was washed with buffer $(20 \mathrm{~mm}$ Tris/HCl buffer, $\mathrm{pH}$ 8.0 , containing $500 \mathrm{~mm} \mathrm{NaCl}, 50 \mathrm{~mm}$ imidazole, $5 \%$ glycerol, $1 \mathrm{~mm}$ THP) at a flow rate of $1.0 \mathrm{~mL} \cdot \mathrm{min}^{-1}$. cACR was eluted from the column with a linear gradient of 50-250 mM imidazole in the same buffer over $30 \mathrm{~mL}$. The resulting fractions were analyzed by SDS/PAGE on a $15 \%$ gel. The fractions containing pure cACR protein were pooled and passed through a PD-10 column (GE Healthcare) for desalting into $50 \mathrm{~mm}$ Tris/HCl buffer, $\mathrm{pH} 8.0,100 \mathrm{~mm} \mathrm{NaCl}, 5 \%$ glycerol, $1 \mathrm{~mm}$ THP and $0.1 \%$ Chaps.

\section{Enzyme assay}

For initial assessment of cACR activity and biochemical characterization of $\mathrm{cACR}$, the assay solution (unless otherwise specified) contained $50 \mathrm{~mm}$ Tris/ $\mathrm{HCl} \quad(\mathrm{pH}$ 7.5), $250 \mathrm{~mm} \mathrm{NaCl}, 2 \mathrm{~mm} \mathrm{MgCl}_{2}, 1 \mathrm{~mm} \mathrm{NADPH}, 0.4 \mathrm{~mm}$ stearoyl-CoA and $10 \mu \mathrm{M}$ purified ACR in a total volume of $250 \mu \mathrm{L}$. The reaction mixtures were incubated at $37^{\circ} \mathrm{C}$ for $1 \mathrm{~h}$. Reaction products were extracted by addition of $250 \mu \mathrm{L}$ ethyl acetate; samples were vortexed for $15 \mathrm{~min}$ 
and then centrifuged in a microfuge at $15000 \mathrm{~g}$. for $20 \mathrm{~min}$ to separate the organic and aqueous phases.

The amount of aldehyde formed was determined by GC analysis of a $10 \mu \mathrm{L}$ sample of the ethyl acetate layer using an Agilent 6890 gas chromatograph equipped with a flame ionization detector (FID). The flow rate of the helium carrier gas was $1.1 \mathrm{~mL} \cdot \mathrm{min}^{-1}$ and the inlet temperature was maintained at $320^{\circ} \mathrm{C}$. Injections were made in split mode with a split ratio of $5: 1$ and a total flow of $5.7 \mathrm{~mL} \cdot \mathrm{min}^{-1}$. The oven temperature was held at $70^{\circ} \mathrm{C}$ for $2 \mathrm{~min}$ and then increased to $280{ }^{\circ} \mathrm{C}$ at $20{ }^{\circ} \mathrm{C} \cdot \mathrm{min}^{-1}$ and finally maintained at $280{ }^{\circ} \mathrm{C}$ for $5 \mathrm{~min}$. The FID was maintained at $260{ }^{\circ} \mathrm{C}$ with a continuous flow of $\mathrm{H}_{2}$ at $40 \mathrm{~mL} \cdot \mathrm{min}^{-1}$ and air at $400 \mathrm{~mL} \cdot \mathrm{min}^{-1}$. Chromatographic data were analyzed using HP CHEM STATION software. Enzymatic conversion of stearoyl-CoA to octadecanal was quantified using a calibration plot of octadecanal.

\section{Kinetic measurements}

cACR activity could also be followed spectrophotometrically through the oxidation of NADPH. Assays were performed at room temperature. The assay buffer contained $50 \mathrm{~mm}$ Tris/ $\mathrm{HCl}\left(\mathrm{pH} \mathrm{7.5),} 250 \mathrm{~mm} \mathrm{KCl}, 2 \mathrm{~mm} \mathrm{MgCl}_{2}\right.$ and $10 \mu \mathrm{M}$ purified ACR. Assays were initiated by addition of NADPH, and cACR activity was measured by following the decrease in absorbance at $340 \mathrm{~nm}$. The rate of NADPH consumption was determined based on $\varepsilon_{340}=6.22$ $\mathrm{mm}^{-1} \mathrm{~cm}^{-1}$. The data were fitted to either a ternary mechanism (Eqn 1) or a 'ping-pong' mechanism (Eqn 2):

$$
\begin{gathered}
v=\frac{V A B}{K_{i a} K_{b}+K_{b} A+K_{a} B+A B} \\
v=\frac{V A B}{K_{b} A+K_{a} B+A B}
\end{gathered}
$$

where $v$ and $V$ are the initial and maximal velocities, and are the substrate concentrations, and are the Michaelis constants for substrates $\mathrm{A}$ and $\mathrm{B}$, and is the dissociation constant for $\mathrm{A}$. The values of the kinetic parameters were determined by global fitting of the kinetic data using the program MATLAB.

\section{Inactivation with iodoacetamide}

Inactivation reactions were performed in $50 \mathrm{~mm}$ Tris $/ \mathrm{HCl}$ ( $\mathrm{pH}$ 8.0) containing $250 \mathrm{~mm} \mathrm{KCl}, 2 \mathrm{~mm} \mathrm{MgCl}_{2}$ and $20 \mu \mathrm{M}$ purified cACR. Reactions were initiated with the addition of IAA to a final concentration of $200 \mu \mathrm{M}$. The reactions were incubated at room temperature in the dark. Aliquots were withdrawn at the indicated time points, quenched by addition of L-cysteine to $1 \mathrm{~mm}$ final concentration and assayed for enzyme activity by following NADPH oxidation. For substrate protection experiments, $200 \mu \mathrm{M}$ stearoyl-CoA was included in the inactivation reactions. As a control, cACR was incubated in the buffer in the absence of IAA and stearoyl-CoA.

\section{Detection of enzyme-thioester intermediate by LC-MS}

Covalent modification of cACR was analyzed using an Agilent 6520 LC accurate-mass Q-TOF MS system. cACR was incubated in the assay buffer with $0.2 \mathrm{~mm}$ NADPH and $0.4 \mathrm{~mm}$ stearoyl-CoA at room temperature for $15 \mathrm{~min}$. As a control, cACR was incubated in the buffer in the absence of NADPH and stearoyl-CoA. The protein was passed through a desalting column and acidified with $0.1 \%$ formic acid. Then $5 \mu \mathrm{L}$ of the sample was injected into a Poroshell 300 SB-C8 column equilibrated with $0.1 \%$ formic acid and $5 \%$ acetonitrile. Proteins were eluted for $5 \mathrm{~min}$ with 95\%: $5 \%$ water : acetonitrile followed by an increasing gradient of acetonitrile to $100 \%$ over $7 \mathrm{~min}$ at a flow rate of $0.5 \mathrm{~mL} \cdot \mathrm{min}^{-1}$. Eluting proteins were detected at $280 \mathrm{~nm}$. Mass data were obtained using intact protein mode and analyzed using Agilent masshunter Qualitative ANALYsis software. The raw data were deconvoluted with respect to maximum entropy.

\section{Acknowledgements}

FL thanks the Michigan Memorial Phoenix Energy Institute for a post-doctoral fellowship. This work was also supported in part by grants from the European Union, FP-7 256808, and NSF, CHE 1152055, to ENGM, and from the NSF, CBET 1055227, to XNL. We thank Dr Andreas Schirmer and Dr William Clay Brown for helpful discussions on the purification of cACR.

\section{References}

1 Kunst L \& Samuels AL (2003) Biosynthesis and secretion of plant cuticular wax. Prog Lipid Res $\mathbf{4 2}$, 51-80.

2 Dennis M \& Kolattukudy PE (1992) A cobaltporphyrin enzyme converts a fatty aldehyde to a hydrocarbon and CO. Proc Natl Acad Sci USA 89, 5306-5310.

3 Vioque J \& Kolattukudy PE (1997) Resolution and purification of an aldehyde-generating and an alcoholgenerating fatty acyl-CoA reductase from pea leaves (Pisum sativum L.). Arch Biochem Biophys 340, 64-72.

4 Wang X \& Kolattukudy PE (1995) Solubilization and purification of aldehyde-generating fatty acyl-CoA reductase from green-alga Botryococcus braunii. FEBS Lett 370, 15-18. 
5 Bourdenx B, Bernard A, Domergue F, Pascal S, Leger A, Roby D, Pervent M, Vile D, Haslam RP, Napier JA et al. (2011) Overexpression of Arabidopsis

ECERIFERUM1 promotes wax very-long-chain alkane biosynthesis and influences plant response to biotic and abiotic stresses. Plant Physiol 156, 29-45.

6 Qui Y, Tittiger C, Wicker-Thomas C, Le Goff G, Young S, Wajnberg E, Fricaux T, Taquet N, Blomquist GJ \& Feyereisen R (2012) An insect-specific P450 oxidative decarbonylase for cuticular hydrocarbon biosynthesis. Proc Natl Acad Sci USA 109, 14858-14863.

7 Peralta-Yahya PP \& Keasling JD (2010) Advanced biofuel production in microbes. Biotechnol J 5, 147-162.

8 Connor MR \& Atsumi S (2010) Synthetic biology guides biofuel production. J Biomed Biotechnol 2010, 9.

9 Rude MA \& Schirmer A (2009) New microbial fuels: a biotech perspective. Curr Opin Microbiol 12, 274-281.

10 Willis RM, Wahlen BD, Seefeldt LC \& Barney BM (2011) Characterization of a fatty acyl-CoA reductase from Marinobacter aquaeolei VT8: a bacterial enzyme catalyzing the reduction of fatty acyl-CoA to fatty alcohol. Biochemistry 50, 10550-10558.

11 Metz JG, Pollard MR, Anderson L, Hayes TR \& Lassner MW (2000) Purification of a jojoba embryo fatty acyl-coenzyme A reductase and expression of its cDNA in high erucic acid rapeseed. Plant Physiol 122, 635-644.

12 Rodriguez A, Wall L, Riendeau D \& Meighen E (1983) Fatty acid acylation of proteins in bioluminescent bacteria. Biochemistry 22, 5604-5611.

13 Reiser S \& Somerville C (1997) Isolation of mutants of Acinetobacter calcoaceticus deficient in wax ester synthesis and complementation of one mutation with a gene encoding a fatty acyl coenzyme A reductase. J Bacteriol 179, 2969-2975.

14 Schirmer A, Rude MA, Li X, Popova E \& del Cardayre SB (2010) Microbial biosynthesis of alkanes. Science 329, 559-562.

15 Das D, Eser BE, Han J, Sciore A \& Marsh ENG (2011) Oxygen-independent decarbonylation of aldehydes by cyanobacterial aldehyde decarbonylase: a new reaction of diiron enzymes. Angew Chem Int Ed Engl 50, 7148-7152.

16 Eser BE, Das D, Han J, Jones PR \& Marsh ENG (2011) Oxygen-independent alkane formation by nonheme iron-dependent cyanobacterial aldehyde decarbonylase: investigation of kinetics and requirement for an external electron donor. Biochemistry 50, 10743-10750.
17 Li N, Nørgaard H, Warui DM, Booker SJ, Krebs C \& Bollinger JM (2011) Conversion of fatty aldehydes to alka(e)nes and formate by a cyanobacterial aldehyde decarbonylase: cryptic redox by an unusual dimetal oxygenase. J Am Chem Soc 133, 6158-6161.

18 Warui DM, Li N, Nørgaard H, Krebs C, Bollinger JM \& Booker SJ (2011) Detection of formate, rather than carbon monoxide, as the stoichiometric coproduct in conversion of fatty aldehydes to alkanes by a cyanobacterial aldehyde decarbonylase. J Am Chem Soc 133, 3316-3319.

19 Andre C, Kim SW, Yu X-H \& Shanklin J (2013) Fusing catalase to an alkane-producing enzyme maintains enzymatic activity by converting the inhibitory byproduct $\mathrm{H}_{2} \mathrm{O}_{2}$ to the cosubstrate $\mathrm{O}_{2}$. Proc Natl Acad Sci USA 110, 3191-3196.

20 Constantinides PP \& Steim JM (1986) Solubility of palmitoyl-coenzyme A in acyltransferase assay buffers containing magnesium ions. Arch Biochem Biophys 250, 267-270.

21 Lee CY \& Meighen EA (1997) Cysteine-286 as the site of acylation of the Lux-specific fatty acyl-CoA reductase. Biochim Biophys Acta Protein Struct Molec Enzym 1338, 215-222.

22 Demmer U, Warkentin E, Srivastava A, Kockelhorn D, Potter M, Marx A, Fuchs G \& Ermler U (2013) Structural basis for a bispecific $\mathrm{NADP}^{+}$and $\mathrm{CoA}$ binding site in an Archaeal malonyl-coenzyme A reductase. J Biol Chem 288, 6363-6370.

23 Kockelkorn D \& Fuchs G (2009) Malonic semialdehyde reductase, succinic semialdehyde reductase, and succinyl-coenzyme A reductase from Metallosphaera sedula: enzymes of the autotrophic 3-hydroxypropionate/4-hydroxybutyrate cycle in Sulfolobales. J Bacteriol 191, 6352-6362.

24 Faehnle CR, Le Coq J, Liu X \& Viola RE (2006) Examination of key intermediates in the catalytic cycle of aspartate-beta-semialdehyde dehydrogenase from a Gram-positive infectious bacteria. J Biol Chem 281, 31031-31040.

25 Faehnle CR, Ohren JF \& Viola RE (2005) A new branch in the family: structure of aspartate-betasemialdehyde dehydrogenase from Methanococcus jannaschii. J Mol Biol 353, 1055-1068.

26 Skarzynski T, Moody PCE \& Wonacott AJ (1987) Structure of holo-glyceraldehyde-3-phosphate dehydrogenase from Bacillus stearothermophilus at 1.8 A resolution. J Mol Biol 193, 171-187. 